\title{
A model to facilitate reflective thinking in clinical nursing education
}

\author{
M Chabeli, Phd., Associate Professor, Department Of Nursing, Rand Afrikaans \\ University \\ M Muller, Phd., Professor, Department Of Nursing, Rand Afrikaans University
}

\section{Abstract}

A qualitative, contextual, exploratory and descriptive design for theory generation was used to develop a model to facilitate reflective thinking in clinical nursing education (Mouton \& Marais, 1990:43; Mouton, 1996: 103109; Chinn \& Kramer 1991:79-120). A model was developed within the existing frameworks of theory generation. Wilson ( 1963:23-39) and Gift (1997:75,76) provided a theoretical framework for a concept analysis of reflective thinking in phase one of the study. Further conceptual meaning was attained through a perceptual survey where twelve nurse educators participated in a focus group interview with regard to how reflective thinking can be facilitated in clinical nursing education. Classification of the main concepts and sub-concepts was made through a conceptualisation process within Dickoff, James and Wiedenbach's (1968:415-435) theoretical framework using the six elements of practice theory.
Concluding relation statements were inferred through deductive analysis and synthesis after conceptualisation of each main concept. The relation statements provided the basis for model description (Chinn \& Kramer, 1991:107-125). Definitions of the main concepts and sub-concepts were described using the basic rules by (Rossouw, 2001:10-11; Cohen \& Copi, 1994:192-195). The adapted educational process from five learning theories provided a framework through which the procedure to facilitate reflective thinking in clinical nursing education was described. Lastly, the model was evaluated using the pre-determined criteria by Chinn and Kramer (1991:128-137) and refined by experts in qualitative research and theory generation. Guidelines were developed which do not form part of this article. Theoretical validity was ensured. Recommendations, limitations, challenging hypothesis and a conclusion were made.

\section{Introduction}

The purpose of this article is to describe a model to facilitate reflective thinking in clinical nursing education. The model was developed through four phases in accordance with the objectives of the study namely; concept analysis of reflective thinking; perceptual survey of nurse educators with regard to how reflective thinking can be facilitated in clinical nursing education; conceptualisation phase; model development and evaluation phase.

The article describing the concept analysis of reflective thinking (unpublished), gives a detailed research method of a concept analysis as described by Wilson (1963:23-39) and Gift (1997:75,76). The results of a concept analysis are indicated in a conceptual map in figure 1 .

The results of the concept analysis provided direction for the perception survey of nurse educators using an agenda focus group on how reflective thinking in clinical nursing education could be facilitated (Chabeli 2004:57-78). Guba and Lincoln (1985:290)'s principles to ensure trustworthiness were employed. The identified main concepts and subconcepts were classified and conceptualised in phase three of the study within the six elements of the practice theory as outlined by Dickoff, James and Wiedenbach (1968: 415435) and Stevens Barnum, (1994:13) namely:

Agent - who or what performs the activity? (The nurse educator as facilitator).

Recipient - who or what is the recipient of the activity? (The learner).

Context - In what context is the activity performed? (Clinical nursing education).

Purpose - What is the end result of the activity (Facilitation of reflective thinking).

Dynamic - What is the energy source for the activity (Interactive discourse).

Procedure - What is the guiding procedure (The three phases of reflective thinking).

The relation statements derived after conceptualisation of each of the six concepts were inferred through the process of deductive analysis and synthesis. The relation statements provided the basis for model development. The model was evaluated in accordance with Chinn \& Kramer (1991:107-125)'s method and refined by experts in qualitative research and model generation. 


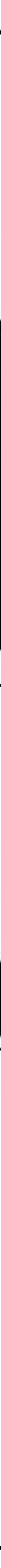

hases of reflective thinking in relation to cognitive and affective thinking skills as ar 
Description of a model to facilitate reflective thinking in clinical nursing education

A model was described in accordance with Chinn and Kramer's (1991:107-125) method as indicated.

1. An overview of the model

2. The purpose of the model

3. The structure of the model which consist of

3.1 The assumptions (meta-theoretical assumptions and theoretical framework)
3.2 Definitions of concepts

3.3 Relation statements and

3.4 The nature of the structure of the model.

4. Process description of the model.

5. Evaluation of the model.

The process and the structure of the model are interrelated in that the description of the process is inherent in the description of the nature of the structure of the model and therefore, the two processes will be described simultaneously.

\section{An overview of the model}

A schematic representation in Figure 6 depicts a model in which the facilitator creates an environment conducive for

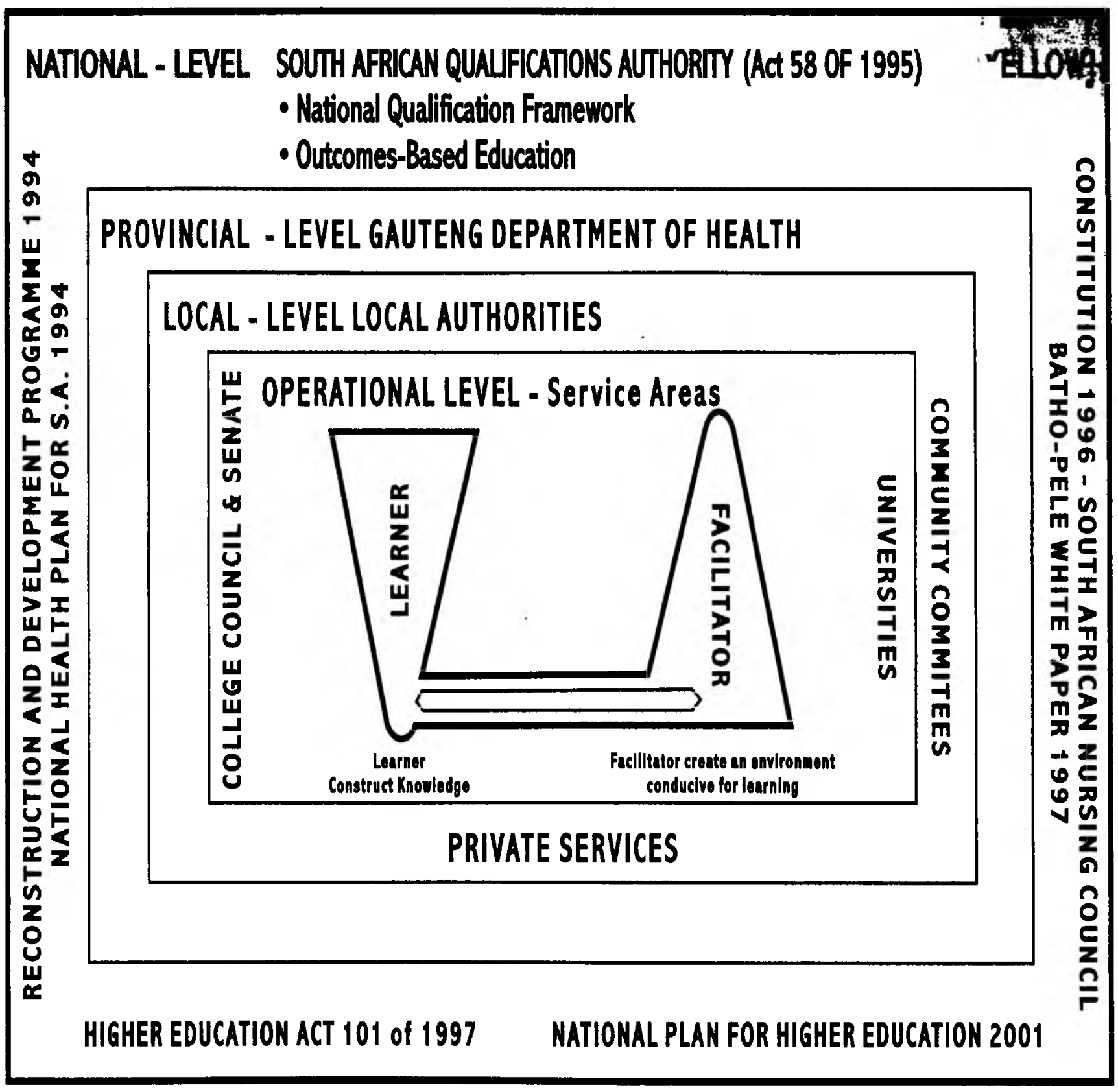

Figure 2. Context: Clinical Nursing Education 


\section{CONTEXT: CLINICAL NURSING EDUCATION}

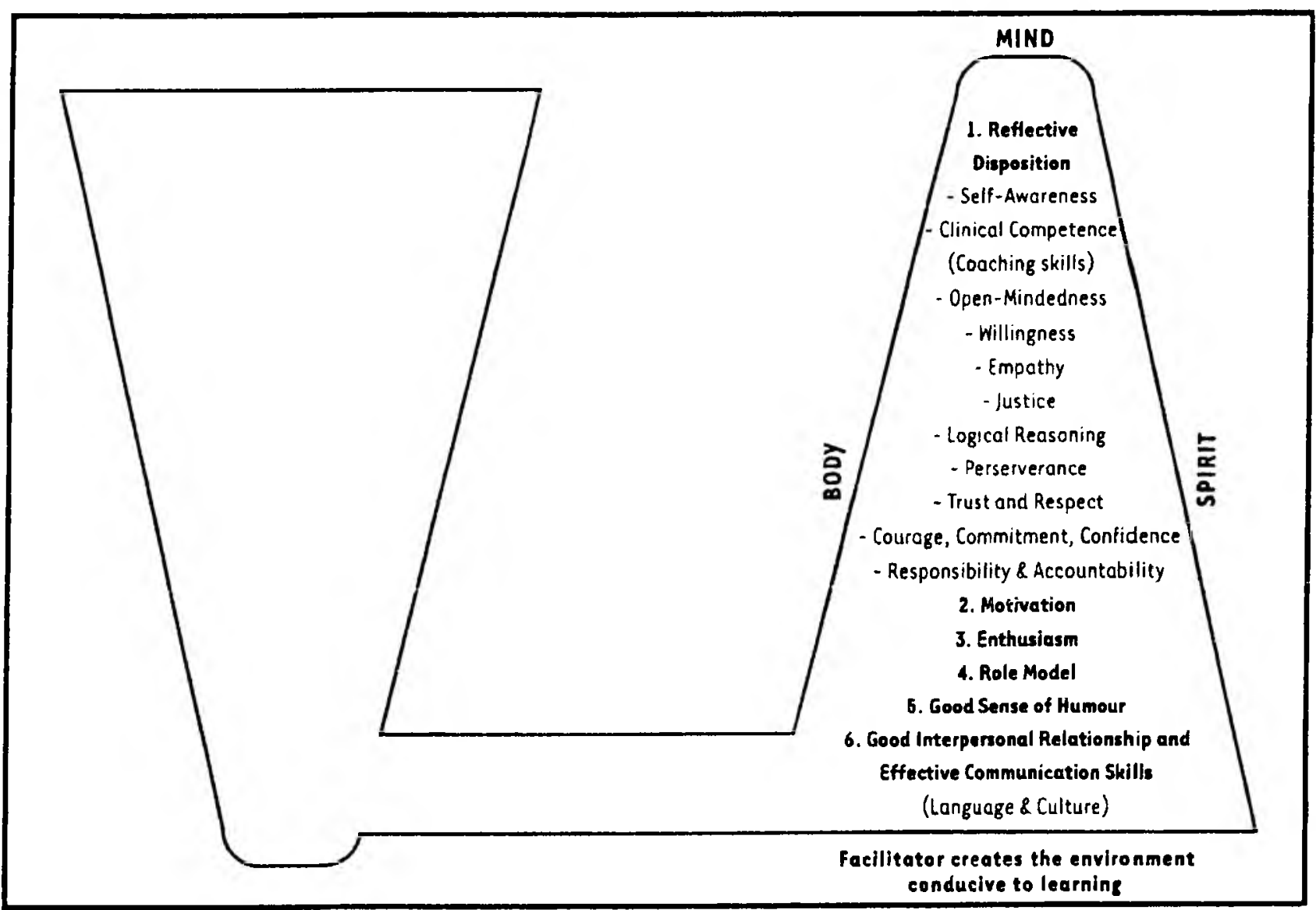

Figure 3. Facilitator: Agent (Characteristics)

active construction of clinical knowledge, skills, attitudes and values through interaction in order to facilitate reflective thinking. Clinical nursing education is the context in which theory and practice are integrated through interactive discourse. It is a dynamic and challenging environment that occurs within the legal and professional boundaries on national, provincial, local and operational levels that have an impact on clinical nursing education (Figure 2).

The facilitator, as depicted in (Figure 3 ) is the agent in this model empowered with reflective dispositions to enable one to create a reflective learning environment that will foster the integration of theory and practice:

The learner is the recipient of the learning activity. The learner should possess characteristics that will drive or sustain the interactive constructing process through discourse to acquire clinical knowledge, skills, attitudes and values in a holistic manner. The learner should be able to practice independently and autonomously, and develop skills of meta-learning for lifelong learning (Figure 4).

The facilitator creates the environment conducive to learning through a dynamic process of interactive discourse (Figure 5). Inherent in the process of discourse is intellectual dialogue, discussions and debates in a specific cultural context, mediated by language competency. The na- ture of the discourse is progressive starting from the lowerences. The interactive facilitation process through discourse is the vehicle through which the procedure to facilitate reflective thinking of learners occurs in clinical nursing education.

The procedure/process takes place by using the three phases of a reflective thinking process as influenced by the related cognitive and affective thinking skills within the adapted educational process framework derived from the five learning theories as described under the nature of the structure below (Vygotsky, 1963; Carl Rogers, 1983; Knowles, 1980; Gagne, 1971 \& Bruner, 1966).

\section{The purpose of the model}

The model intends to demonstrate how reflective thinking of learners in clinical nursing education can be facilitated. This intention is realised through the utilization of the three phases of reflective thinking within the framework of the adapted educational process. The facilitator creates the environment conducive to learning through the interactive facilitation process that is progressive in nature, by using appropriate clinical teaching strategies, assessment and evaluation methods that facilitate the learner's active construction of knowledge, skills, attitudes and values. 


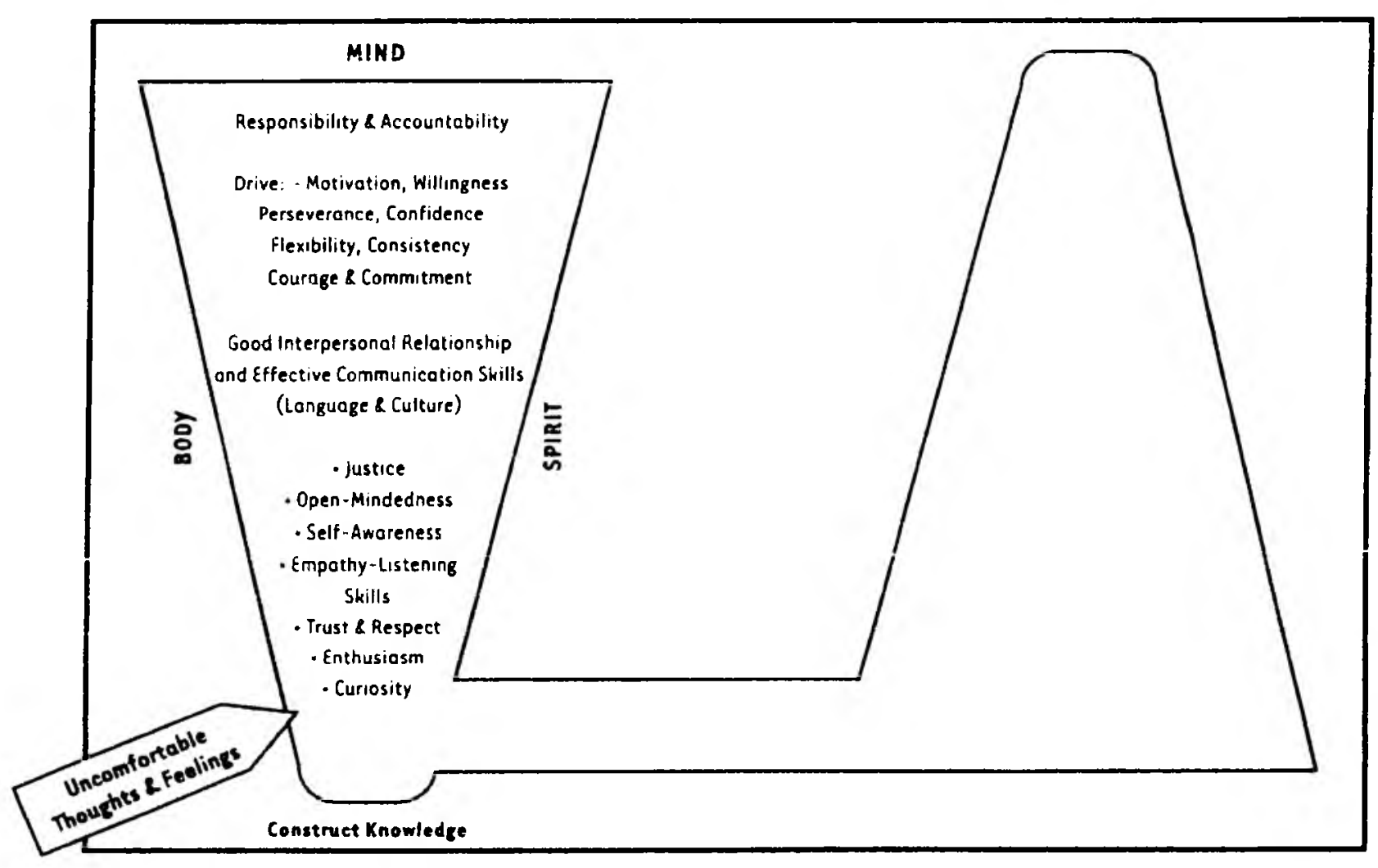

Figure 4. The Learner: Recipient (Characteristics)

\section{The structure of the model}

According to Chinn and Kramer (1991:107-125), the structure of the model consists of the assumptions on which the model is based; definitions of the main concepts; relation statements and the nature of the structure.

\section{- Assumptions}

The researcher believes that the facilitator and the learner in clinical nursing education context are unique, holistic beings who interact with the social environment in an integrated manner to promote learning. The reflective mind is seen as part of the broader context. The social construction of meaning through active creation of own knowledge and skills, as influenced by the cognitive and affective thinking skills, are in continuous interaction, mediated by meaningful linguistic interaction and dialogue in a specific cultural context. The learner has the potential for learning and intellectual development.

The researcher believes that the clinical nursing education context is a socially constructed world that creates and is constrained by the shared experiences of the underlying physical activity to promote learning through a reflective thinking process. The environment itself is constantly changing.

Interactive facilitation is a dynamic interpersonal, interac- tive process whereby the learner is capable of continuous intellectual growth and development through discourse in a specific social and cultural context. Interactive facilitation leads the learner to have potential for new learning and making positive changes in practice.

The following theoretical frameworks helped the researcher to establish some boundaries when designing the research plan. The researcher had to familiarise herself with the different phases of reflective thinking described by these authors in order to derive the three phases of reflective thinking in this study (Dewey 1933:12,107-1 14, Boud, Keough \& Walker 1985, Atkins \& Murphy 1993:1190, Boyd \& Fales 1983: 106, and Bloom's taxonomy (1956).

\section{- Definitions of concepts}

The identified concepts classified according to the practice theory by Dickoff, James and Wiedenbach (1968:415435 ) integral to the model are as follows: clinical nursing education (context), the facilitator (agent), the learner (recipient), the interactive facilitation (dynamic), the three phases of reflective thinking as influenced by the cognitive and affective thinking skills (procedure) and the (purpose) - facilitation of reflective thinking. These central concepts were defined by using the five rules of definition as described by (Rossouw, 2000/01: 10,11 and Copi \& Cohen, 1994:192-195). 


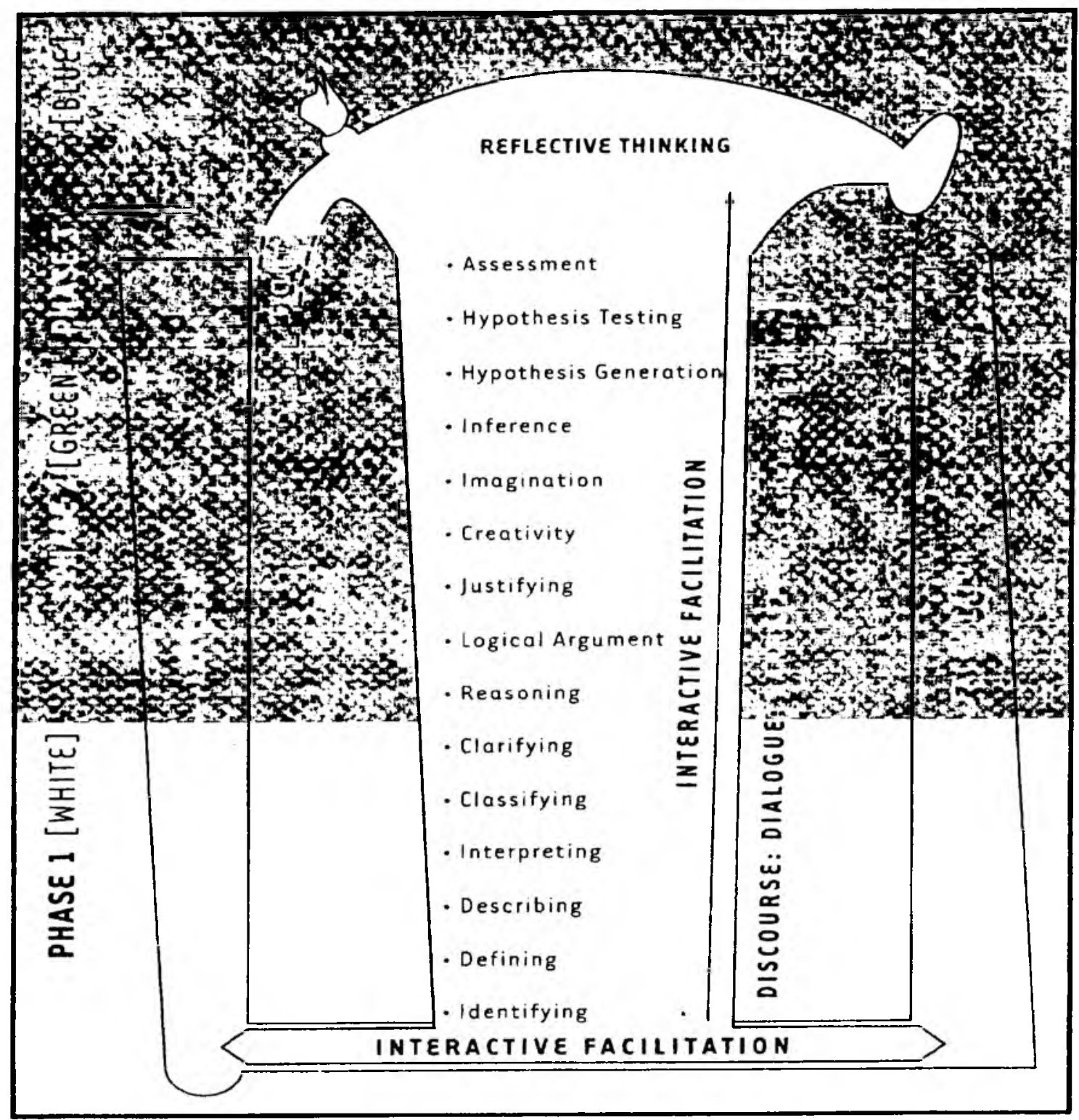

Figure 5. Interactive facilitation: dynamic

\section{Clinical nursing education - (context)}

Clinical nursing education is a dynamic constantly changing, real-life environment in which theoretical knowledge is integrated with practice. The facilitator is responsible for creating the environment conducive to learning, while the learners should take responsibility in the construction of their own knowledge and skills through interactive discourse to promote reflective thinking. Clinical nursing education occurs within the legal and professional boundaries.

\section{Facilitator (agent)}

The facilitator refers to a nurse educator registered with the South African Nursing Council (SANC) as a nurse educator with expert knowledge and clinical competence. Facilitators should be in possession of the enabling characteristics to facilitate reflective thinking of learners by creating the environment conducive to learning through an interactive facilitation process in clinical nursing education.

\section{Learner (recipient)}

A person who follows a four-year comprehensive course leading to registration with the SANC as a nurse (general, psychiatry, community) and midwife is a learner in this study. For reflective thinking to be facilitated, learners should possess enabling characteristics in order to actively participate in the construction of their own knowledge, skills, attitudes and values under the guidance and support of the facilitator through interaction in clinical nursing education. The learner is expected to practice independently and autonomously in practise.

\section{Interactive facilitation (dynamic)}

Interactive facilitation is a dynamic, mutual, interactive proc- 


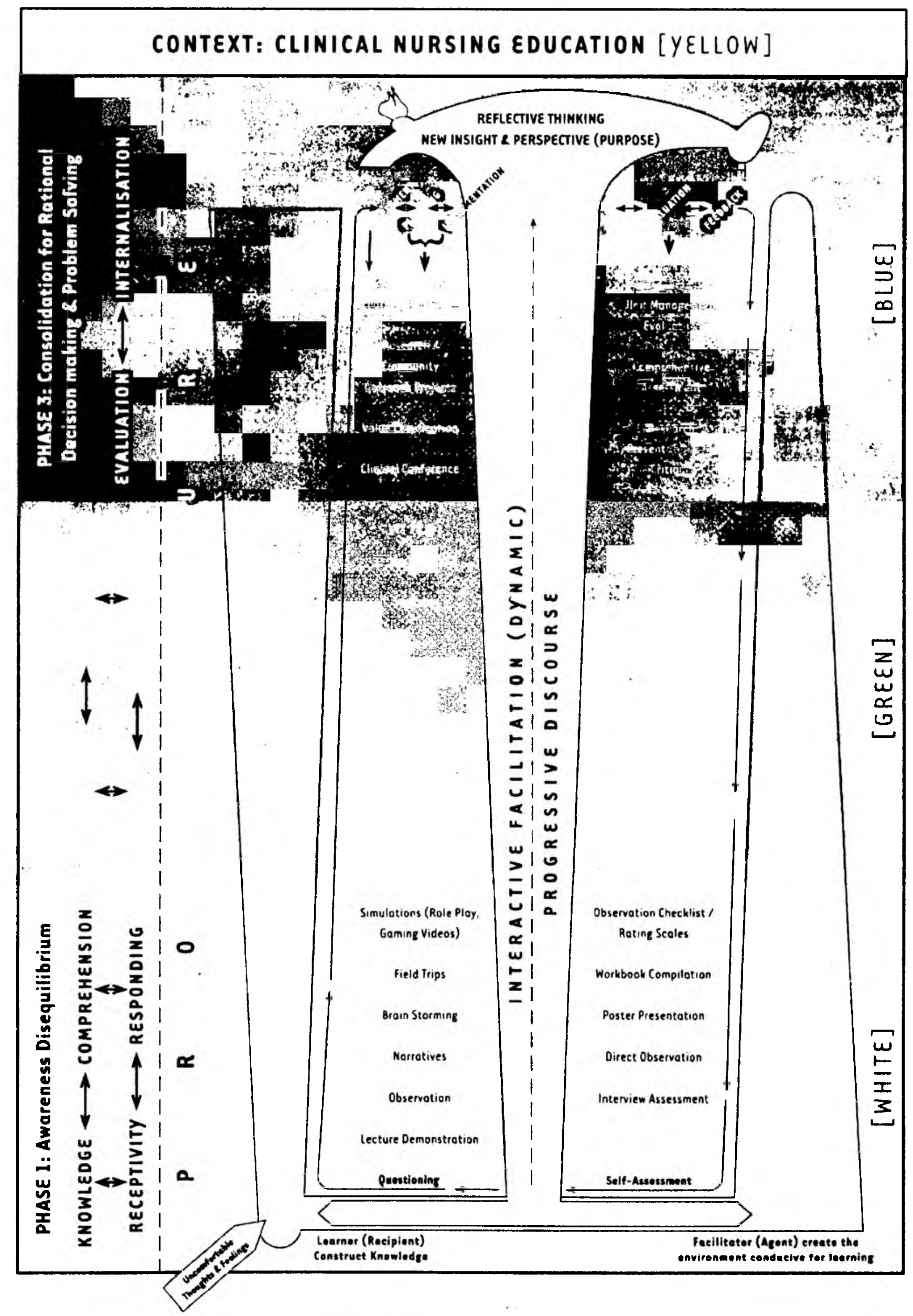

Figure 6 . Facilitating reflective thinking 
ess between the learner and the facilitator or the environment with the quest to facilitate reflective thinking of learners through interactive discourse in clinical nursing education.

\section{Reflective thinking (purpose)}

In this study, reflective thinking is a rational, progressive interactive mental process influenced by cognitive and affective thinking skills. It is triggered by uncertainty in a specific situation, bringing about a state of awareness and disequilibrium, which leads to an interactive constructing process followed by consolidation of knowledge, resulting in the creation of new insight and a changed perspective for independent decision making and problem solving in practice.

\section{Reflective thinking process (procedure)}

The reflective thinking process occurs in three phases as influence by their related hierarchical cognitive and affective thinking skills in clinical nursing education (Blooms taxonomy, 1956). The elements of the three phases will be defined categorically.

\section{Phase 1: Awareness and disequilibrium (influenced by knowledge and receptivity, comprehension and responding thinking skills)}

- Awareness is a skill of recognition stimulated by uncomfortable thoughts and feelings or uncertainty in a situation.

- Disequilibrium refers to a disturbance in the search for mental balance. The situation does not satisfy the learner; it is queer, and the learner becomes uncomfortable due to lack of knowledge in a given situation.

- Knowledge denotes factual knowledge of the basic essentials of a discipline. Such knowledge forms the basis for one to think reflectively. It refers to self and contextual domain specific knowledge.

- Receptivity refers to the ability to quickness in receiving impressions or ideas; the attitudinal state of the learner to acquire knowledge, skills, attitudes and values in clinical nursing education.

- Comprehension refers to the learner's ability to interpret (summarise or explain information in the learner's own words), translate (paraphrase a communication while maintaining the intent of the original), and extrapolate (when information is projected beyond the given data).

- $\quad$ Responding is the ability to show answers in words and feelings. The response depends on the willingness, motivation and enthusiasm of the learner.

\section{Phase 2: Interactive constructing process (influenced by analysis and valuing, synthesis and organisational thinking skills)}

- The interactive constructing process refers to a mutual, collaborative exchange of ideas, thoughts and feelings between the learners and the facilitator, environment, and between the learners themselves in the quest to make meaning by constructing their own clinical knowledge, skills, attitudes and values through discourse.

- Analysis refers to the process of breaking down information into its constituent parts for the purpose of detailed examination of the elements or structure of the information for better interpretation and understanding.

- Valuing is defined as having a high or specified opinion of, or attaching importance to: developing an attitude of worth by the learner towards a phenomenon.

- Synthesis refers to the process of building up separate elements, especially ideas, thoughts and feelings into a connected whole. Creativity and imagination are necessary to view issues with a different, new perspective.

- Organisation is the ability of give orderly mental structure to information for meaning making.

\section{Phase 3: Consolidation of knowledge for rational decision-making and problem-solving (influenced by evaluation and internalisation thinking skills)}

- Consolidation refers to integration and synthesis of clinical knowledge, skills, attitudes and values by the learner, based on an existing conception. The learners develop new insight and changed perspectives that enable them to make rational decisions and solve problems. The learner can practise independently and autonomously.

- Evaluation is determining the worth, accuracy or completeness of something; judging, appraising and assessing a situation.

- Internalisation refers to making thoughts and feelings part of one's nature by learning or unconscious assimilation, to be incorporated as part of the internal structure. The learners incorporate professional values as part of their nature for making future, rational clinical decisions and solving problems.

- Decision making refers to the selection of an alternative from a number of alternatives to achieve a goal.

- $\quad$ Problem solving refers to working out a correct solution to an uncertain or perplexing situation or to a perceived difficult problem.

\section{- Relation statements}

The relation statements of the model are inherent within the definitions of the key and their related concepts.

\section{- The nature of the structure and the process description of the model}

To make it possible to follow the reasoning of the development of this model to facilitate reflective thinking in clinical nursing education, the nature of its structure and the proc- 
ess description of the model will be described simultaneously because of the nature of their interrelatedness. The schematic representation of the model is depicted by figure 6. All the six central and related conceptual relationships are included within a single structure.

The rectangular or outside border in yellow depicts the clinical nursing education as a dynamic, constantly changing context conducive to learning through interaction for the purpose of facilitating the learner's reflective thinking. The facilitator, in partnership with other stakeholders responsible for clinical teaching, creates the environment conducive to learning by mobilising resources and using the appropriate clinical teaching, assessment and evaluation methods to enable the learners to construct their own learning. Clinical nursing education takes place within the legal and professional boundaries at national, provincial, local and operational levels indicated in Figure 2. The outside borders are coloured yellow to depict the positive, optimistic and constructive nature of the environment as described by de Bono (1970)'s thinking hat. The learners positively explore practice by taking calculated risks, exploring all the available avenues exposed to them, continuously and actively constructing their knowledge, skills, attitudes and values through interactive discourse.

The upright triangle in Figure 3, depicts the facilitator who possesses the enabling characteristics to create a positive environment conducive to learning. The appropriate characteristics are as indicated: the reflective disposition evidenced by self-awareness/ self-worth, expert clinical knowledge and skills, open and fair-mindedness, willingness, empathy, justice, logical reasoning, perseverance, trust, respect, courage, commitment, confidence, responsibility and accountability. Motivation, enthusiasm, role-modelling, a good sense of humour, good interpersonal relationships and communication skills play an integral part in facilitating reflective thinking in clinical nursing education.

The interactive facilitation to create the environment conducive to learning provided by the facilitator tapers as the learner takes responsibility for self-directed learning. Initially the facilitation is mostly instructional and less conversational. Hence, the broader base of the triangle in the first phase where basic domain specific and self-knowledge are acquired.

As the learner develops intellectually, the facilitator's input encourages the engagement of learners in progressive discourse. The apex of the triangle is narrow to indicate the marked reduction of the facilitator's input in interactive facilitation of reflective thinking. The learner is taking control in self-directed learning and monitoring as demonstrated by the ability to make rational clinical decisions and solving of problems. The learner is expected to be self-disciplined and to practise independently and autonomously.

The inverted triangle, figure 4 , depicts the learner in the process of constructing clinical knowledge and skills. Learners should possess the characteristics that provide them with the energy to take part in discourse, such as the intel- lectual curiosity, enthusiasm, empathy, good listening skills, mutual trust and respect. Self-awareness, self-worth, open and fair-mindedness, justice, good interpersonal relationships and communication skills in a specific culture with language competency as a mediator also play an important role. Drive in the form of motivation, willingness, perseverance, flexibility, consistency, confidence, courage, commitment, responsibility and accountability are supporting dispositions to reflective thinking. The narrow portion of the triangle in phase one indicates the lack of domain specific and self-knowledge, which makes the learner facilitatordependent.

In the second phase, the triangle becomes broader as learners begin to take active participation in their own learning. The facilitator is responsible for creating a positive environment that will encourage dialectic and dialogic interaction amongst learners. Learners are expected to use logical reasoning and justifying their decisions through arguments based on evidence. The learner becomes intellectually willing, empathetic and courageous to interact with others in order to construct clinical knowledge and skills (Paul 1993:471).

The broadest portion of the inverted triangle lies in the third phase to indicate that the learner is able to view situations comprehensively with new insight and a changed perspective. The learner is able to consolidate the knowledge and experience and use it to make rational clinical decisions and solve problems with little guidance from the facilitator. At this level the input made by the facilitator is viewed as 'interfering' by the learner. The learner is expected to practise independently and autonomously and to have acquired lifelong learning skills.

The inverted double-pointed T-shaped tube between the learner and the facilitator, within the inverted pyramid ends up with a broad burning lamp (Figure 6). The inverted Tshaped tube represents the interactive facilitation process through discourse as the underlying dynamic to facilitate reflective thinking. The double points demonstrate the interaction between learners who constructs their own knowledge and skills, and the facilitator who creates the environment conducive to learning. The broadening vertical aspect of the $T$ indicates the progressive discourse that takes place through dialogical reasoning, co-operative and collaborative learning in a non-judgmental, fair environment where learners can take risks and verbalise innovative ideas.

The interactive facilitation takes the form of a progressive discourse as evidence by the lower part of the $T$ in the first phase being narrow because the facilitator uses teaching strategies, assessment and evaluation methods that are mostly instructional. The input of the learner is minimal. Learners basically have to learn to identify, define and describe concepts in order to acquire basic knowledge and skills. To facilitate comprehension, the learner is expected to interpret, classify and clarify information and experience based on prior knowledge.

The diameter of the T-shaped tube in the second phase 
increases as it progresses upward to indicate the degree of active participation of the learners in constructing their own knowledge and skills through interaction. The learner is expected to engage in arguments, making use of logical reasoning to justify decisions and actions made based on the available evidence. To facilitate synthesis and organisation skills, the learner uses creativity and imagination, draws inferences according to principles, and generates hypotheses based on the available knowledge and skills in order to create new insight and changed perspectives. The extent of the discourse is influenced by linguistic clarity in mediating cognitive development within a specific social and cultural context

The broadest part of the T-shape tube lies in the third phase since the learner is expected to test the generated hypotheses in order to validate the relationships and draw valid conclusions. The learner is expected to make appropriate assessments and evaluate the information for its worth, accuracy, relevancy and acceptability in a specific situation. The evaluated information is internalised to enable the learner to make rational decisions and solve problems in practice. The learner is able to practice independently and autonomously with little or no guidance from the facilitator. It is at this level (Figure 6) that reflective thinking is said to have taken place as demonstrated by the broad burning lamp that signifies the bright, holistic and comprehensive nature of the clinical nursing education perceived by the learner.

The double-pointed vertical and horizontal arrows indicate the interaction between the phases, the cognitive and affective thinking skills that influence the phases, the facilitator, the learner and the educational process. There is no rigid law with regard to the use of the teaching and evaluation methods (Figure 6). The success of the teaching and evaluation methods depends on the flexibility and creativity of the facilitator, as well as the willingness, flexibility, receptivity and responsiveness of the learner. One teaching strategy could be used on a simpler scale in one group and more complex in a senior group.

The top part of the teaching and evaluation strategies (Figure 6) is the adapted educational process as demonstrated by the process of assessment, planning, implementation, evaluation and feedback connected by the descending feedback loop. The double-pointed arrows in between the dimensions indicate that the logical sequence may not be followed accordingly, depending on the context in which the educational process occurs. They also indicate that the assessment findings, the planning, the implementation and the evaluation methods should correlate with the intellectual development of the learner. The logical development of the structures serves as a conceptual map to enhance the clarity, comprehensibility and evaluation of the model.

The structure of the reflective thinking process is described through the following three distinct, yet interdependent phases used within the adapted educational process namely, the awareness and disequilibrium (phase 1); the interactive constructing process (phase 2) and the consolidation (phase 3) to make rational decisions and solve problems.

Aspects of the educational process (figure 6), as advocated by educational psychologists took the nursing process format of assessment of the learners' prior knowledge and background, planning the learning environment to facilitate reflective thinking, implementation of the planned learning activities, assessment and evaluation methods and the provision of feedback to learners (Vygotsky, 1963; Carl Rogers, 1983; Knowles, 1980; Gagne, 1971 \& Bruner, 1966).

The awareness and disequilibrium is the first phase of the reflective thinking process triggered by the uncomfortable thoughts and feelings of the learner in a given situation due to the lack of self- and domain specific knowledge as demonstrated by a pointing arrow to the narrow part of the learner. At this stage, the learner tends to ask reflective self-questions such as: What is happening here? Who am I? What knowledge do I have? Do I have the necessary tools to deal with the situation? What is my philosophy regarding the situation? What alternatives do I have? Given a chance, would I make the difference, and how? These questions make the learner engage in self-assessment and self-reflection to establish any gaps in knowledge. Questioning or pre-tests can be given to the learners to assess their pre-existing knowledge in a specific discipline. The facilitator's input is greatest in this phase since the learners lack basic clinical knowledge. The assessment findings will assist the facilitator to plan and implement the teaching strategies, assessment and evaluation methods in relation to the learner's level of intellectual development.

At this level, learners usually learn how to identify, define and describe concepts, principles, protocols and theories to guide their actions. These operational thinking skills can be facilitated through strategies such as questioning, lecture demonstration, and observation under guided practice, and they should be encouraged to write descriptive stories (narratives) concerning their experiences or what was significant to their experience, whether negative or positive. At this level the learners should learn to do selfassessment, be exposed to interviews and subject themselves to direct observation of performance through continuous assessment and evaluation. The atmosphere of open-mindedness and genuine interest will enhance the acquisition of the knowledge and skills followed by the facilitation of comprehension of the acquired knowledge. The colour is white because, according to de Bono (1970), the white hat symbolizes purity and refers to basic knowledge such as pure facts, concepts, principles and theories. Basic knowledge forms the building blocks of reflective thinking (Van der Horst \& McDonald, 1997:218).

Comprehension and responsiveness thinking skills form part of the first phase. To facilitate comprehension and responsiveness, the facilitator still has to assess the learners' existing conception by asking self-generated questions. They also encourage learners to pause frequently and perform a self-check for understanding to determine whether 
or not comprehension has actually occurred. Questions such as interpret, classify, clarify and paraphrase can help assess the comprehension ability of the learner. Thereafter, the facilitator can plan, and implement teaching strategies such as brainstorming, field trips, simulations in the form of role-play, gaming and video clinical activities to facilitate comprehension and the responsiveness of the learner to the situation.

The learner's willingness, motivation, enthusiasm, linguistic clarity and cultural sensitivity will play a significant role in enhancing the comprehension of information in a specific context. The facilitator should encourage learners to participate actively in their own learning and consider each other's value system. At this level, the assessment and evaluation methods that could be used are, amongst others, poster presentations, where learners can share ideas and feelings on how a poster should be developed in order to interpret an idea, theme or event meaningfully. Workbooks can be used, if well planned. Direct observation plays a major role at this level since nursing is procedureladen at this stage.

Phase two, the interactive constructing process lies in the middle between horizontal lines (figure 6). This phase is coloured green because of its creative, interacting manner of generating new insight and perspective and the need for originality acquired through dialogue and discourse (de Bono, 1970). Learners take an active role in the constructing of their own learning, and the teacher assumes the role of a facilitator. According to de Bono, a green hat thinker is not impulsive and can elaborate on ideas by going beyond the obvious and including new dimensions. This is a typical characteristic of creativity attained through critical analysis and synthesis, taking into consideration the values and the organising ability of the learner to generate new insight and changed perspectives useful for making rational clinical decision and solving problems.

Active participation of learners in constructing their own knowledge and skills should be facilitated through teaching strategies and evaluation methods that promote discourse. Learners are encouraged to be analytical and to develop an enquiring mind by asking thought-provoking questions, debating issues, applying logic, justifying their decisions and actions through inductive and deductive reasoning and to validate the evidence put forth. Learners must not succumb to the argument but they must learn to defend their stand logically based on justified evidence. They must learn to ask questions to facilitate the drawing of cause and effect relationships, analysing, synthesising, compare and contrasting the content and making meaningful interpretation and relationships. The facilitator should assess the learner's existing conception to be able to plan appropriate teaching strategies such as reflective journal writing, nursing process including case studies, peer tutoring and concept mapping in order to stimulate interaction resulting in the facilitation of the learner's reflective thinking. Learners are compelled to analyse and synthesise thoughts and actions and to translate them into symbolic form, to write the processes of strategic thinking and decision making. Learners are expected to use dialogical reasoning during arguments and to justify their decisions based on the appropriate existing evidence through dialogic discussion and probing for elaboration.

This cognitive activity is driven by dispositions such as intellectual empathy with good listening skills, mutual respect and a trusting relationship, confidence and courage to engage actively in dialogue and discourse. Similarly, the assessment and evaluation methods, such as peer assessment and critical incident technique will serve the same purpose. To facilitate synthesis and organising thinking skills of the learner, the facilitator will have to challenge the learners even more by creating hypothetical situations that require the learner's creative and imaginative ability, to draw inferences and generate hypotheses in clinical nursing education. Learners should be challenged by the process of finding answers and challenged by ambiguous situations. The use of analogies, metaphors and generalisations will help to facilitate the process of synthesis and organisation to demonstrate the "Aha" feeling created by the emerging new insight and the ability to view situations in a different holistic perspective.

To sustain learners in active construction of their own knowledge and skills in clinical nursing education, learners should possess characteristics such as: intellectual perseverance, flexibility, and consistency. They should be systematic in creating different patterns, ideas and themes together to make a meaningful contribution. As learners become more flexible in their thinking, they can be heard considering, expressing or paraphrasing another person's point of view or rationale. They can give several ways to solve the same problem and can evaluate the merits and consequences of actions.

Teaching and learning are invigorated with increased opportunities for dialogue such as group projects, seminars and workshops where issues are debated, interpreted and justified using logical arguments and validated in the light of convincing and appropriate evidence. The assessment and evaluation method require team-work, collaborative, co-operative thinking and active participation by learners themselves, such as, amongst others, portfolio assessment and reflective tutorials.

The third phase of reflective thinking is involved with the consolidation of all the knowledge and skills gained through experience to improve practice independently and autonomously. The colour is blue because, according to de Bono (1970), learners who wear the blue thinking hat are cool and do not panic. They are in control of their learning. They call for the use of different thinking hats to make decision and solve problems. They are able to monitor and evaluate their whole thinking process and make internalised professional values their own for future use in practice. This assertion characterises the learner in the third phase, where reflective thinking is inevitable.

In phase three of reflective thinking process, learners are expected to be in control of their own learning. Self-directed, self-regulated learning is the hallmark of this phase. The facilitator's input is limited whereas that of the learner is maximised as learners take responsibility and accountability for their own learning. However, the facilitator's diagnostic "cognitive map" of the learner's thinking becomes more sharpened. There is mutual assessment and 
planning of the appropriate learning outcomes, teaching strategies, mobilisation of resources, clinical learning opportunities, the assessment and the evaluation methods. Application of knowledge at this level invites learners to think creatively and generate hypothetical problems themselves, use their imagination, expose or apply the value system of self or others, or make critical judgement. Learners make use of the complex thinking activities. They assess the learning situation through critical analysis and synthesis, make rational decisions, solve problems independently and autonomously based on justice, referred to as 'intellectual fairness' by Rossouw; Lotter; Serfontein: Snyman and Van Vuuren (1994:7).

Appropriate teaching strategies, assessment and evaluation methods should encourage team work, team building, co-operation and partnership, such as clinical conferences involving the client or significant others, with members of other disciplines, where ideas, thoughts and feelings can be shared and tested. Value clarification plays an important role in ethical decision making in clinical nursing education because of its collaborative and cooperative nature guided by empathy and respect for other people's values. Research / community outreach projects play an integral part in this phase because of the inquiring/research-minded and explorative nature to gain new knowledge, or to accept or refute the existing conception in a specific clinical practice. The involvement of the community, local authorities and other stakeholders in the community research projects strengthens partnerships and team-work in the implementation of community-based education that is learner-centred and learner-friendly. Self-directed learning contracts facilitate reflective thinking as learners take responsibility for self-assessment, -regulating, -monitoring and -control in their own learning. The assessment and evaluation methods also involve teamwork, collaboration and the involvement of other stakeholders in the education and training of learners. Research paper presentations and critiquing presented in small groups in the presence of expert researchers, service authorities, community members and other stakeholders challenge the learners' higher order thinking ability, and make them feel part of the team. Ownership feeling of learners in the learned activities is enhanced.

Comprehensive assessment of knowledge gained in all the four disciplines of nursing in one objective structured clinical examination (OSCE) is challenging to both the facilitator and the learner. The learner has to demonstrate the ability to consolidate and integrate the acquired knowledge, skill, attitudes and values from the four disciplines of nursing (general, community, psychiatric) and midwifery supported by the fundamental courses such as physics, chemistry, pharmacology, anatomy, physiology, microbiology and social science. It needs to be planned jointly, involving the learners whose learning needs are to be met. A mutually, well developed criteria for the assessment and evaluation process need to be established. The importance of a ward round and unit management assessment and evaluation cannot be over-emphasised in this phase. The learner should demonstrate the ability to manage the ward/unit efficiently in keeping with the set standards in order to make rational clinical decisions and solve problems independently and autonomously. Peer assessment in this re- gard should be encouraged to promote learning and to build up the learner's confidence.

In all the phases, facilitators should encourage immediate feedback aimed at building the learner and to establish the strengths and weaknesses of the learner and the facilitator. A post-conference evaluation session in a relaxed atmosphere is advocated (Chabeli 1998:41).

The process of the model to facilitate reflective thinking in clinical nursing education occurs in a dynamic and complex environment within the legal, ethical and professional context. Challenged by the changing dynamics in clinical practice, learners will find themselves in a situation in which they lack knowledge and skills in a different situation. This will cause the learner to experience discomfort and uncertainties and the cycle of reflective thinking will begin again as demonstrated by the descending mouth of the lamp back to the acquisition of specific knowledge (Figure 6).

\section{Evaluation of the model}

The study was supervised by two experts in model development and qualitative research. One supervisor is an expert and is versatile with ethical, educational and philosophical issues. The other is an expert in nursing management, versatile with the management of clinical learning units, where the facilitator has to create the environment conducive to learning. Further more, phase one of the model (concept analysis of reflective thinking), was evaluated internationally by a panel of experts and experienced teacher educators in an international education conference held in the year 2000. Locally, the model was presented to a doctoral research committee of five and other invited research experts, making the evaluation of the model meaningful and comprehensive. The model was also evaluated on the basis of predetermined criteria of theory generation as described by (Chinn \& Kramer 1991:129).

\section{Limitations}

The concept analysis was based on relevant literature to determine the meaning and uses of reflective thinking in clinical nursing education. The empirical phase from the nurse educators was focussed only on how reflective thinking could be facilitated in clinical nursing education based on the results of the concept analysis. It was not a national survey, but it was confined to one province, which makes it difficult to make generalisations. This model still needs to be implemented, tested and refined.

\section{Recommendations}

Recommendations are made with reference to practice, nursing education and research. Nursing practice is referred to as "a fertile experience in learning how to learn" (Reilly \& Oerman, 1985:4). It is thus important that guidelines for the implementation of the model in the form of varied dialogic, learner-centred, learner-friendly teaching and evaluation methods be communicated to the scientific community in nursing education so as to be able to implement them in facilitating reflective thinking of learners. It has become imperative that facilitators investigate the didactic validity 
of each of these methods and the relevant media. Each media has a unique function in the practice of teaching and learning.

Fraser et al, (1993:166) argue that the utilisation of each method should be researched continually to ensure effective instruction and learning. Clinical nursing education should focus on research that deals with the "how of learning" that is, how to facilitate critical and reflective thinking skills as the ultimate learning outcome of educational programmes to improve practice. Practice related action research and interdisciplinary research are encouraged to improve practice (Cerinus, 1994:35). Readers may be challenged with the testing of the following hypothesis: Reflective thinking in clinical nursing education can be facilitated through the use of interactive, collaborative learner-centred teaching and evaluation methods.

\section{Concluding remarks}

A model to facilitate reflective thinking of learners in clinical nursing education has been described within the selected theoretical frameworks. The implementation of the model will rely on the use of the teaching and evaluation methods intentionally by nurse educators followed by their refinement through further research. Nursing is a peopledriven profession and thus should justify its "worth" as a caring profession by producing critical and reflective thinkers who will be able to deliver the service competently with dignity and integrity. We, as a scientific community of nurse educators should strive for excellent and vibrant clinical nursing education. We should be committed to refine or generate new teaching, assessment and evaluation methods that will "give birth to critical, reflective and selfauthored, self-disciplined thinking learners" by creating the environment and clinical learning opportunities that will develop critical capacities of learners in the interest of transforming education for improved practice (Weil \& Anderson, 2000).

\section{References}

ATKINS, S \& MURPHY, K 1993: Reflections: A review of the literature. Journal of Advanced Nursing ( 18), 1188-1192.

BLOOM BS ed. 1956: Taxonomy of educational objectives. The classification of educational goals. New York: McKay.

BOUD D; KEOUGH R \& WALKER D 1985: Reflection: Turning experience into learning. London: Routledge and Kegan Paul.

BOYD, EM \& FALES, AW 1983: Reflective learning: Key to learning from experience. Journal of Humanistic Psychology. 23(2). 99-117.

BURNS, RN \& GROVE, SK 1993: The practice of nursing research, conduct, critique and utilisation. Philadelphia: W.B Saunders Company.

BRUNER, JS 1966: Towards a theory of instructions. New
York: Norton.

CERINUS, M 1994: Preparing nurses for preceptorship. Nursing Standard. 8(36), June, 35-41.

CHABELI, MM 2004: Nurse educators'perceptions on facilitating reflective thinking in clinical nursing education. Health SA Gesondheid 9(1):57-78.

CHABELI, MM 2001: A model to facilitate reflective thinking in clinical nursing education. Doctoral Thesis. Rand Afrikaans University.

CHABELI, MM 1998: Professional nurses as reflective clinical learning facilitators. Curationis. June 1998: 39-44.

CHINN, PL \& KRAMER, MK 1991: Theory and nursing: A systematic approach. St. Louis: Mosby Yearbook.

COPI \& COHEN, IM 1994: Introduction to logic. New York: The Macmillan Publishing Company.

DE BONO, E 1970: Lateral thinking: Creative step-by step New York: Harper and Row.

DEWEY, J 1933: How we think. A restatement of the relation of reflective thinking to the educative process. Lexington, Massachusetts.

DICKOFF, J; JAMES, P \& WIEDENBACH, E 1968: Theory in a practice discipline. Part 1: Practice orientated theory. Nursing Research 17(5), September - October, 415 435.

FRASER, WJ; LOUBSER, CP \& VAN ROOY, MP 1993: Didactics for the undergraduate student. Durban: Butterworth Publishers.

GAGNE, RM 1971: The conditions of learning. London: Holt, Rinehart \& Winston Routledge \& Kegan Paul.

GIFT, AG 1997: Clarifying concepts in nursing research. Pennsylvania: Springer Publishing Company.

GUBA, EG \& LINCOLN, YS 1985: Naturalistic inquiry. London: Sage Publications.

KNOWLES, M 1980: The modern practice of adult education: From pedagogy to andragogy. New York: The Adult Company.

MIIES, MB \& HUBERMAN, AM 1994: Qualitative data analysis. London: Sage Publications.

MOUTON, J \& MARAIS, HC 1990: Basic concepts in methodology of the social sciences. Pretoria: Human Science Research Council.

MOUTON, J 1996: understanding social research. Pretoria: JL van Schaik Publishers. 
MORSE, J 1994: Critical issues in qualitative research methods. London: Sage Publications.

PAUL, R 1993: What every person needs to survive in a rapidly changing world: critical thinking. Santa Rosa, CA: Foundation for Critical Thinking.

REILLY, DE \& OERMAN, MH 1985: The clinical field. Its use in nursing education. Norwalk, Connecticut: Appleton.

ROGERS, CR 1983: Freedom to learn for the 80's. Columbus, Ohio: Charles E. Merrill.

ROSSOUW, D 2001: Intellectual tools. Pretoria: Amabhuku Publications.

ROSSOUW, GL; LOTTER, HPP; SERFONTEIN, P; SNYMAN, J \& VAN VUUREN, PJJ 1994: Skilful thinking. An introduction to philosophical skills. Pretoria: HSRC Publisher.

STEVENS-BARNUM, BJ 1994: Nursing theory, analysis, application and evaluation. Philadelphia: JB. Lippincott Company.

VAN DER HORST, H \& McDONALD, R 1997: Outcomesbased education. A teacher's manual. Pretoria: Kagiso.

VYGOTSKY, LS 1963: Learning and mental development at school age. Cambridge MA: MIT Press.

WEIL, D \& ANDERSON, HK 2000: Perspectives in critical thinking. New York: Peter Lang Publishing, Inc.

WELLS, G 2000: Dialogic inquiry in education: Building on the legacy of Vygotsky.

http://www.oisc,utoronto.ca/ gwells/NCTE.html

WILSON, J 1963: Thinking with concepts. Cambridge. Cambridge University Press. 